\title{
Evaluation of the Candida sp. 99-125 Lipase Positional Selectivity for 1,3-Diolein Synthesis
}

\author{
Yanhong Bi $\left(\mathbb{D},{ }^{1}\right.$ Zhangqun Duan, ${ }^{2}$ Wenjing Zhang, ${ }^{1}$ Lei Xu, ${ }^{1}$ Zhaoyu Wang $\left(\mathbb{D},{ }^{3,4}\right.$ \\ Xiaojuan Zhao, ${ }^{3,4}$ Xiangjie Zhao, ${ }^{1}$ and Jiali Yang ${ }^{1}$ \\ ${ }^{1}$ School of Life Science and Food Engineering, Huaiyin Institute of Technology, Huaian 223003, China \\ ${ }^{2}$ Academy of State Administration of Grain, Beijing 100037, China \\ ${ }^{3}$ Faculty of Chemical Engineering, Huaiyin Institute of Technology, Huaian 223003, China \\ ${ }^{4}$ Jiangsu Key Laboratory of Regional Resource Exploitation and Medicinal Research, Huaian 223003, China
}

Correspondence should be addressed to Zhaoyu Wang; biowzy@126.com

Received 4 March 2019; Revised 3 May 2019; Accepted 7 May 2019; Published 20 May 2019

Academic Editor: Isabelle Chevalot

Copyright (C) 2019 Yanhong Bi et al. This is an open access article distributed under the Creative Commons Attribution License, which permits unrestricted use, distribution, and reproduction in any medium, provided the original work is properly cited.

\begin{abstract}
In this study, comparative experiments were carried out to investigate the positional selectivity of Candida sp. 99-125 lipase in preparing 1,3-diolein by using medium engineering strategy. The results indicated that the diolein yield was markedly enhanced from $56.5 \%$ to $86.7 \%$ with increasing $\log P$ values of the solvents, while the selectivity of the examined lipase for the $s n-1$ over the $s n-2$ hydroxyl of glycerol was decreased, thus leading to a reduced 1,3-diolein to 1,2-diolein ratio. To evaluate the possibility of industrial enzymatic production of 1,3-diolein, larger-scale experiments were assessed. After being used repeatedly for eight batches, the diolein content reached $95.1 \%$, while the 1,3-diolein to 1,2-diolein ratio was 7:1 following purification. Results of the $\mathrm{kg}$ level experiments significantly demonstrated the practicability of the enzymatic process and the efficiency of the purification strategy for the product.
\end{abstract}

\section{Introduction}

1,3-Diacylglycerol has positive impacts on lowering the body-fat buildup and eluding an increase in weight $[1,2]$. The synthesis of 1,3-diacylglycerol via enzyme approaches has garnered greater attention, due to their environmental friendliness, safety, exquisite selectivity, and mild reaction conditions [3-6]. Meanwhile, 1,2-diacylglycerol, which is a positional isomer, can be produced at the same time. Thus, the positional selectivity of the enzyme utilized becomes pivotal to attain the elevated 1,3-diacylglycerol yield.

As the reaction media have a significant impact on selectivity of an enzyme, numerous papers have documented the impact of the physicochemical characteristics of the solvent on the selectivity of the utilized enzyme [7-9]. It has been suggested that $\log P$, which is the logarithm of the partition coefficient of a solvent in the standard octanol-water two-phase system, was more practical [10-12].
Further, the documented lipases (e.g., Novozyme 435 and Lipozyme RM IM) for 1,3-diacylglycerol generation are costly. A commercially available cheap lipase from Candida sp. $99-125$ has been proved to be quite effective to catalyze preparation of fatty esters such as biodiesel, monoacylglycerol, and diacylglycerol by esterification from fatty acids $[5,13$, 14]. In addition, to the best of our knowledge, the positional selectivity of Candida sp. 99-125 lipase in the preparation of 1,3-diacylglycerol is seldom examined. In particular, no evaluation has been noted as examining the how the positional selectivity of Candida sp. 99-125 lipase is influenced by the reaction media. As a result of this, we now explore the work to examine the impact of the $\log P$ values of the solvents on the positional selectivity of Candida sp. 99-125 lipase, in which the model reaction for 1,3-diolein synthesis was the oleic acid esterification with glycerol. Moreover, the largerscale experiments, operational stability of the enzyme, and purification of 1,3-diolein were also conducted to additionally 


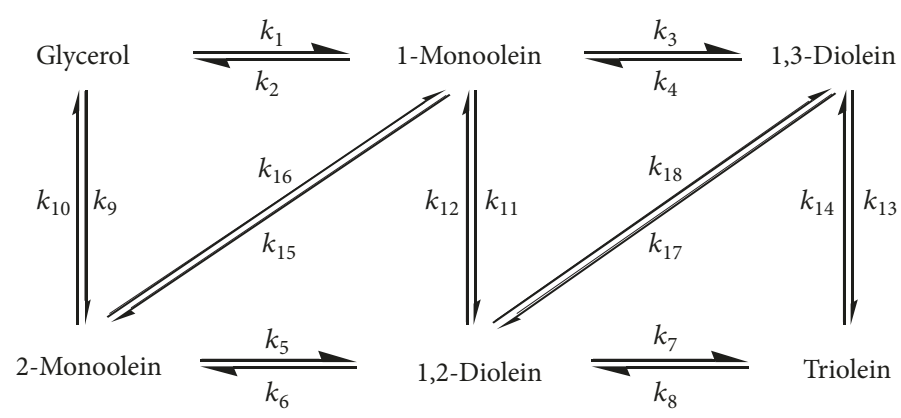

SCHeme 1: The lipase-mediated esterification of oleic acid with glycerol.

evaluate the possibility of using Candida sp. 99-125 lipase for the industrial generation of 1,3-diolein.

\section{Materials and Methods}

2.1. Materials: Candida sp. 99-125 lipase (lyophilized powder) was bought from Beijing CTA New Century Biotechnology Co., Ltd. The amount of protein was $370 \mathrm{mg}$ protein/g enzyme powder, as determined by the Bradford assay. The standard substances of 1-monoolein, 2-monoolein, 1,2diolein, 1,3-diolein, and triolein were acquired from SigmaAldrich. The mobile phases of HPLC were chromatographically pure acetonitrile and dichloromethane. The rest of the chemicals and reagents were of analytical grade and commercially acquired.

2.2. Assaying of Enzyme Activity. The enzyme's esterification activity was determined by the model reaction of oleic acid esterification by glycerol. In the usual experiment, the following reagents were combined and incubated at $50^{\circ} \mathrm{C}$ at $200 \mathrm{rpm}$ in a shaking 50-mL Erlenmeyer flask topped with a septum: $8.9 \mathrm{mmol}$ oleic acid, $3.0 \mathrm{mmol}$ glycerol, $1.6 \mathrm{~g} 4 \AA$ molecular sieves, and the enzyme. One unit was quantified as the portion of enzyme that catalyzed the esterification of $1 \mathrm{mmol}$ oleic acid with glycerol per minute, and the specific activity of the enzyme was $34.5 \mathrm{U} / \mathrm{g}$.

2.3. Procedure for Preparation of 1,3-Diolein. The Candida sp. 99-125 lipase-mediated esterification of oleic acid by glycerol was carried out in a $50-\mathrm{mL}$ flask on a rotary shaker at 200 $\mathrm{rpm}$ at $50^{\circ} \mathrm{C}$. The makeup of the reaction was $1.52 \mathrm{mmol}$ oleic acid, $0.60 \mathrm{mmol}$ glycerol, $10 \mathrm{~mL}$ solvent, and $1.52 \mathrm{U}$ Candida sp. 99-125 lipase. 4 A molecular sieves (270 mg) were added to adsorb water. Specimens $(50 \mu \mathrm{L})$ were obtained and centrifuged to obtain the supernatant for subsequent HPLC and GC analysis.

2.4. Analysis of the Samples. 1-Monoolein, 2-monoolein, 1,2diolein, 1,3-diolein, and triolein contents in the reaction combination were examined according to the method of Duan et al. [8]. Shimadzu 20A HPLC with ELSD (evaporative light scattering detector) was used. External standards (1-monoolein, 2-monoolein, 1,2-diolein, 1,3-diolein, and triolein) were used to prepare eight concentrations of calibration solutions. A $2-\mu \mathrm{L}$ sample and $1 \mathrm{~mL}$ acetone were fully combined. The chromatographic column was a C18 column $(5 \mu \mathrm{m}, 250 \mathrm{~mm} \times 4.6 \mathrm{~mm}$ ) (Dikma Technology, PLATISIL ODS, China). A gradient elution with acetonitrileacetic acid (99.85/0.15)/dichloromethane was used for the reaction mixture analysis $(0-4.0 \mathrm{~min}, 100 / 0 ; 4.0-12.0 \mathrm{~min}$, 90/10; 25.0-30.0 min, 70/30; 35.0-45.0 $\mathrm{min}, 20 / 80$; 55.0-60.0 $\mathrm{min}, 100 / 0)$. The flow rate was controlled at $1.5 \mathrm{~mL} / \mathrm{min}$. The column temperature and drift pipe temperature were $40^{\circ} \mathrm{C}$ and $70^{\circ} \mathrm{C}$, respectively, and the nitrogen pressure was 320 $\mathrm{kPa}$. The retention times were $3.75 \mathrm{~min}, 4.54 \mathrm{~min}, 23.12 \mathrm{~min}$, $23.90 \mathrm{~min}$, and $42.91 \mathrm{~min}$ for 2-monoolein, 1-monoolein, 1,3diolein, 1,2-diolein, and triolein, respectively. Oleic acid and glycerol were established via the procedures documented by Du et al. [15]. All of the documented data are averages of experiments conducted at minimum in duplicate.

2.5. Identification of Rate Constants. To investigate the kinetic behaviors in Candida sp. 99-125 lipase-mediated process of preparing 1,3-diolein in tested solvents, the synthetic process is depicted in Scheme 1. The reaction rates follow second-order kinetics except the acyl migration rates (follow first-order kinetics) $[3,16]$; the mass transfer limitation is neglected. According to these assumptions, the differential equations are documented as follows, and OA, 1-MO, 2-MO, 1,3-DO, 1,2-DO, TO, and Gly refer to oleic acid, 1-monoolein, 2-monoolein, 1,3-diolein, 1,2-diolein, triolein, and glycerol in the equations, respectively.

$$
\begin{aligned}
& \frac{d[O A]}{d t}=k_{2}[1-M O]+k_{10}[2-M O]+k_{4}[1,3 \\
& -D O]+\left(k_{6}+k_{12}\right)[1,2-D O]+\left(k_{8}+k_{14}\right)[T O] \\
& \quad-\left(\left(k_{1}+k_{9}\right)[G l y]+\left(k_{3}+k_{11}\right)[1-M O]\right. \\
& \left.+k_{5}[2-M O]+k_{7}[1,2-D O]+k_{13}[1,3-D O]\right) \\
& \cdot[O A] \\
& \frac{d[1-M O]}{d t}=k_{1}[O A][G l y]+k_{4}[1,3-D O] \\
& +k_{12}[1,2-D O]+k_{16}[2-M O]-\left(k_{2}+k_{5}\right. \\
& \left.+\left(k_{3}+k_{11}\right)[O A]\right)[1-M O]
\end{aligned}
$$




$$
\begin{aligned}
& \frac{d[2-M O]}{d t}=k_{6}[1,2-D O]+k_{9}[O A][G l y]+k_{15}[1 \\
& \quad-M O]+\left(k_{5}[O A]+k_{10}+k_{16}\right)[2-M O] \\
& \frac{d[1,3-D O]}{d t}=k_{3}[1-M O][O A]+k_{14}[T O] \\
& \quad+k_{18}[1,2-D O]-\left(k_{4}+k_{13}[O A]+k_{17}\right)[1,3 \\
& \quad-D O] \\
& \frac{d[1,2-D O]}{d t}=\left(k_{5}[2-M O]+k_{11}[1-M O]\right)[O A] \\
& \quad+k_{8}[T O]+k_{17}[1,3-D O]-\left(k_{6}+k_{7}[O A]+k_{12}\right. \\
& \left.\quad+k_{18}\right)[1,2-D O] \\
& \frac{d[T O]}{d t}=\left(k_{7}[1,2-D O]+k_{13}[1,3-D O]\right)[O A] \\
& \quad-\left(k_{8}+k_{14}\right)[T O] \\
& \frac{d[G l y]}{d t}=k_{2}[1-M O]+k_{10}[2-M O]-\left(k_{1}+k_{9}\right) \\
& \quad \cdot[O A][G l y]
\end{aligned}
$$

The rate constants were acquired by solving the equations above utilizing the adaptive step-size Runge-Kutta strategy in the nonlinear regression method by the Levenberg-Marquardt algorithm, to obtain the best fit among the experimental data and the results determined $[3,16]$. The rate constants of concern for the positional selectivity of Candida sp. 99-125 lipase are shown in Table 1.

2.6. Lipase-Mediated Larger-Scale 1,3-Diolein Synthesis. The enzymatic esterification was conducted in a $50-\mathrm{mL}$ Erlenmeyer flask topped with a septum on a rotary shaker at 200 $\mathrm{rpm}$. The reaction mixtures included the following: oleic acid (fixed at $35.4 \mathrm{mmol}$ ), glycerol, $t$-butanol, and Candida sp. 99-125 lipase. 4 A molecular sieves were utilized for adsorbing the byproduct water, and the amount added was 10 times the predicted water quantity. Fifty-microliter samples were removed, and they were centrifuged to obtain the supernatant for subsequent HPLC and GC analysis. The routine singlefactor experiments were applied for the process optimization.

2.7. Operational Stability of Candida sp. 99-125 Lipase. The reactions were performed under optimized conditions in larger-scale experiments $(35.4 \mathrm{mmol}$ oleic acid, $11.8 \mathrm{mmol}$ glycerol, $34.5 \mathrm{U}$ Candida sp. 99-125 lipase, $6.0 \mathrm{~mL} t$-butanol, $6.4 \mathrm{~g} 4 \AA$ molecular sieves, $50^{\circ} \mathrm{C}$, and $7 \mathrm{~h}$ ) acquired by the typical single-factor experiments in a 50 - $\mathrm{mL}$ flask on a rotary shaker at $200 \mathrm{rpm}$. When the reaction was completed, the lipase powders and the molecular sieves were divided from the reaction via filtration with Whatman \#1 filter paper and then rinsed with $t$-butanol in a Buchner funnel minus filter paper. The lipase powders and $t$-butanol could pass the holes of Buchner funnel, while the molecular sieves not. Thus, the molecular sieves were isolated from the lipase powders which can be separated with $t$-butanol by filtration using Whatman $\# 1$ filter paper and then directly used during the further batch.

2.8. The Kg Level Experiments. The enzymatic esterification proceeded in a $5.0 \mathrm{~L}$ stirred tank reactor at $200 \mathrm{rpm}$. The reaction combinations are as follows: $3.54 \mathrm{~mol}$ oleic acid, 1.18 mol glycerol, $0.6 \mathrm{~L} t$-butanol, and $3450 \mathrm{U}$ Candida sp. 99-125 lipase. $4 \AA$ molecular sieves were included to adsorb the byproduct water. The $5-\mathrm{mL}$ samples were removed and centrifuged to obtain the supernatant for evaluation.

2.9. Purification of 1,3-Diolein. After the reactions, the enzyme powders and the molecular sieves were separated by filtration, and then the reaction mixtures were transferred to a rotary evaporator (BUCHI, R-215, Switzerland), in which the reaction media $t$-butanol could be removed at $40^{\circ} \mathrm{C}$ when the vacuum was $130 \mathrm{mbar}$. The purification of 1,3-diolein was performed on a molecular distillation (UIC GmbH, KDL5, Germany) at $180^{\circ} \mathrm{C}$ and 0.1 mbar.

\section{Results and Discussion}

It is well known that the enzyme performance depends very much on the type of the reaction medium, for example, widely different activity and selectivity are observed with different nature of the organic solvent $[18,19]$. With the goal of preparing 1,3-diolein, the solvents with $\log P$ values from -0.23 to 4.5 acted as the reaction media for the esterification of oleic acid with glycerol catalyzed by Candida sp. 99-125 lipase. Diolein yields are provided in Table 1 (column 5). As one can see, the diolein yield obviously relied on the polarity characteristics of the reaction media. The lowest diolein yield $(56.5 \% \pm 1.5 \%)$ occurred in acetone with the smallest $\log P$ value $(-0.23)$. Moderate values were acquired in the comparably hydrophilic solvents (Table 1, Entries 25). Greater diolein yields were attained in the hydrophobic solvents (Table 1, Entries 6-11). When the reaction media were $n$-hexane, $n$-heptane, and $n$-octane, greater than $86 \%$ yield was achieved. In addition, reaction times were noticeably different in each of the solvents. The reaction time was lowered with the increasing $\log P$ values, which suggested that enzyme activity was greater in the higher $\log P$ solvent. The higher enzyme activity involved in this case might be attributable to the fact that the solvents with greater $\log P$ could retain the microenvironment moisture surrounding the active area of Candida sp. 99-125 lipase to a greater extent, resulting in a more stable conformation of the enzyme, thereby eluding the deactivation that occurs as a result of the lack of essential water [20,21].

In contrast, the 1,3-diolein to 1,2-diolein ratio shown in Table 1 (column 6) was significantly impacted by the reaction media. The largest ratio of 1,3-diolein to 1,2-diolein (28.3) was documented in the most hydrophilic solvent (acetone). The 1,3-diolein to 1,2-diolein ratio was lowered quickly with the elevating $\log P$ value. The lowest 1,3-diolein to 1,2 -diolein ratio was 5.2 , which was observed in $n$-octane (the most hydrophobic solvent). Specifically, the 1,3-diolein 


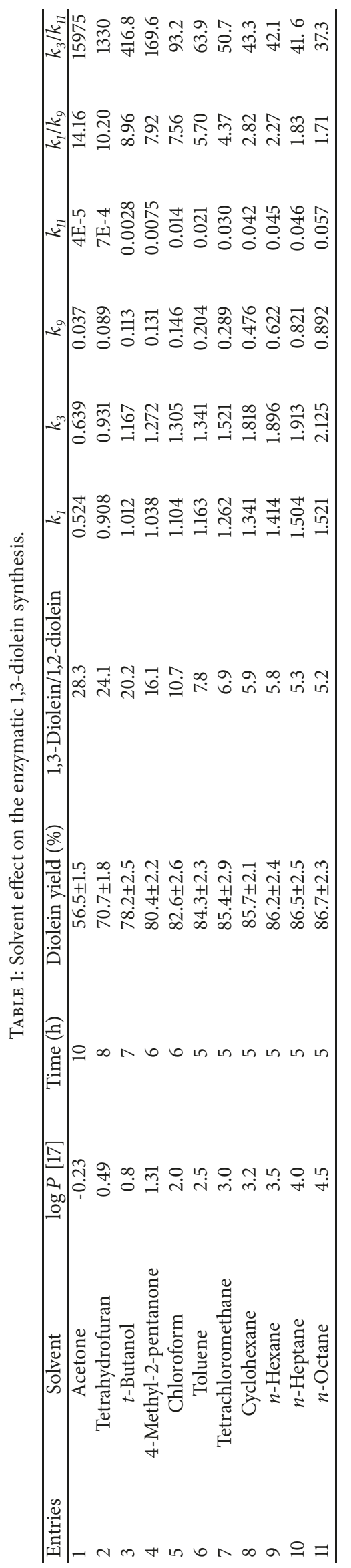


to 1,2-diolein ratio was influenced substantially in the tested hydrophobic solvents (Table 1, Entries 6-11), which impacted diolein yield to a minor extent. As is recognized, the ratio of 1,3-diolein to 1,2-diolein relied on the favorable selectivity of Candida sp. 99-125 lipase for the $s n-1$ hydroxyl over the $s n$ 2 hydroxyl of glycerol and the migration of the acyl group (which can be neglected due to the minor impact; data not shown).

According to the above results, a detailed evaluation of the positional selectivity of Candida sp. 99-125 lipase based on medium engineering was explored. From Table 1 (columns $7-10$ ), it can be viewed that $k_{1}, k_{3}, k_{9}$, and $k_{11}$ were improved with the increasing $\log P$ values. It substantially improved the diolein yield that occurred from the rise of $\log P$ value. $k_{1}$ was larger than $k_{9}$ in each of the tested solvents, demonstrating that the particular selectivity of Candida sp. 99-125 lipase towards the $s n-1$ hydroxyl of glycerol was far greater than the one to the $s n-2$ hydroxyl. However, the increase times of $k_{1}$ were substantially less than those of $k_{9}$ with increasing $\log P$ values. Therefore, $k_{1} / k_{9}$ was lowered obviously (from 14.16 to 1.71$)$. It was shown that the favorable selectivity of Candida sp. 99-125 lipase towards $s n-1$ hydroxyl over $s n-2$ hydroxyl became lessened with the increase in solvent $\log P$ values. When the reaction media were $n$-hexane, $n$-heptane, and $n$-octane, the values of $k_{1} / k_{9}$ were $2.27,1.83$, and 1.71 , respectively. As the amount of $s n-1$ hydroxyl was two times the $s n-2$ hydroxyl in glycerol, if the value of $k_{1} / k_{9}$ was near 2.00 , it could be seen that the particular selectivity of Candida sp. 99-125 lipase towards $s n-1$ hydroxyl and $s n-2$ hydroxyl was comparable. It is beneficial for generating 2-monoolein and 1,2-diolein utilized as emulsifiers or surfactants in the food industry $[22,23]$.

In addition, while the $k_{3}$ increase times were smaller than those of $k_{11}$ with the rise of $\log P$ values, $k_{3}$ was still noticeably larger than the correlated $k_{11}$, so that $k_{11}$ could be ignored. It was demonstrated that the particular selectivity of Candida sp. 99-125 lipase towards the $s n-1$ hydroxyl of 1monoolein was noticeably greater than the one towards the $s n-2$ hydroxyl in each of the tested solvents. Further, $k_{3} / k_{11}$ was larger than $k_{1} / k_{9}$ in all of the solvents, indicating that the greater preferential selectivity of Candida sp. 99-125 lipase to the $s n-1$ hydroxyl over the $s n-2$ hydroxyl occurred in the molecule of 1-monoolein.

Based on the attained outcomes mentioned above, the diolein yield was higher, while the preferential selectivity of Candida sp. 99-125 lipase to the $s n-1$ hydroxyl over the $s n-2$ hydroxyl of glycerol was lessened, leading to a decreased 1,3diolein to 1,2 -diolein ratio in the solvent with greater $\log P$ values. Thus, the relatively hydrophilic solvent of $t$-butanol was chosen as the best medium for Candida sp. 99-125 lipasemediated 1,3-diolein preparation.

To additionally evaluate the possibility of using Candida sp. 99-125 lipase for the industrial production of 1,3-diolein, studies on the larger-scale experiments, operational stability of lipase, and 1,3-diolein purification were developed. The impact of some substantial reaction factors including the reaction temperature, amount of lipase, the oleic acid to glycerol molar ratio, and the amount of $t$-butanol were examined systematically by routine single-factor experiments

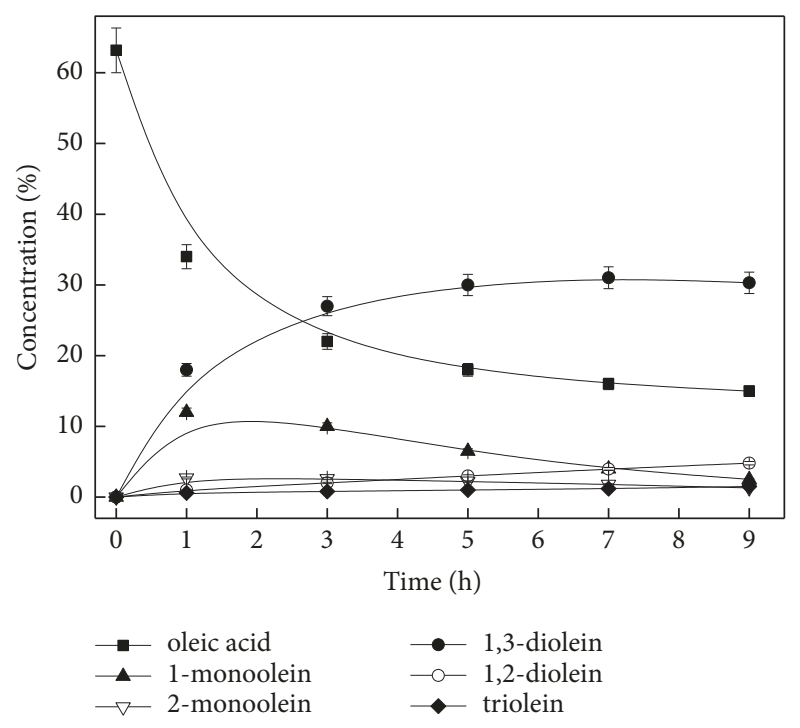

Figure 1: The time course of the esterification of oleic acid with glycerol for 1,3-diolein synthesis catalyzed by Candida sp. 99-125 lipase. Reaction conditions: $35.4 \mathrm{mmol}$ oleic acid, $11.8 \mathrm{mmol}$ glycerol, 34.5 U lipase, $6.0 \mathrm{~mL} t$-butanol, and $6.4 \mathrm{~g} 4 \AA$ molecular sieves, $50^{\circ} \mathrm{C}$.

(data not shown). The outcomes revealed that diolein yield and the 1,3-diolein to 1,2-diolein ratio attained $75.3 \%$ and 7.8 , respectively, with the optimal reaction conditions (35.4 mmol oleic acid, $11.8 \mathrm{mmol}$ glycerol, $34.5 \mathrm{U}$ Candida sp. 99-125 lipase, $6.0 \mathrm{~mL} t$-butanol, and $6.4 \mathrm{~g} 4 \AA$ molecular sieves, $50^{\circ} \mathrm{C}, 7 \mathrm{~h}$ ). Under reaction conditions that were optimal, the process curves of Candida sp. 99-125 lipasemediated esterification method to prepare 1,3-diolein are shown in Figure 1. Besides the substrate concentration (oleic acid) and the target product (1,3-diolein), the concentration of the intermediates (1-monoolein) and the by-products (2monoolein, 1,2-diolein, and triolein) are also revealed. As can be observed, the biggest concentration of 1,3-diolein was achieved at $7 \mathrm{~h}$.

Following the reaction, Candida sp. 99-125 lipase was divided via filtration and then used in the following batch with the goal of understanding the enzyme's operational stability. Figure 2 shows enzyme activity which was characterized by the 1,3-diolein concentration at the end of the reaction as a function of the reaction batch, in which batch 0 is the 1,3-diolein concentration catalyzed by fresh lipase in the initial trial, which was determined to be $100 \%$. One can see that $82.4 \%$ of the initial activity remained after eight batches, suggesting that this lipase is cost-effective.

Furthermore, the product was purified by the rotary evaporation for solvent removing followed by the molecular distillation for the removal of the excess oleic acid and byproducts. $t$-Butanol is a commercial solvent obtained from isobutylene and has emerged as a stable medium for drugs and spices synthesis. It is a relatively nontoxic compound with acute effects similar to ethanol and has high vapor pressure $\left(31 \mathrm{~mm} \mathrm{Hg}\right.$ at $\left.20^{\circ} \mathrm{C}\right)$ and low boiling point $\left(82.8^{\circ} \mathrm{C}\right)$ for easy recovery. In this experiment, $t$-butanol separated by the rotary evaporation could be recycled for the synthetic 
TABLE 2: The contents of various components during the purification process (\%).

\begin{tabular}{lccccccc}
\hline & $t$-Butanol & Oleic acid & 1-Monoolein & 2-Monoolein & 1,3-Diolein & 1,2-Diolein & Triolein \\
\hline Before solvent removal & 29.94 & 19.12 & 5.96 & 2.13 & 31.02 & 3.98 & 1.55 \\
After solvent removal & - & 29.97 & 9.22 & 3.47 & 48.47 & 6.42 \\
After molecular distillation & - & - & - & - & 83.33 & 11.81 \\
\hline
\end{tabular}

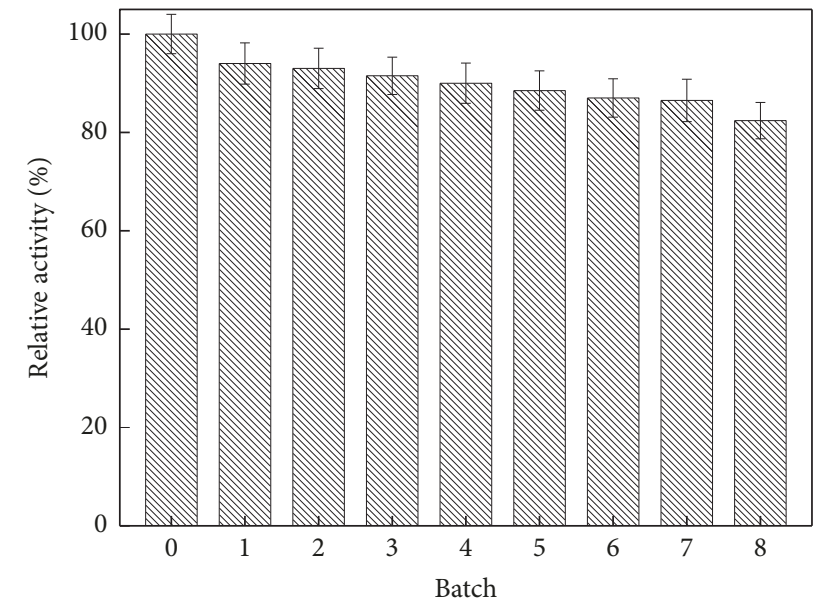

Figure 2: The operational stability of Candida sp. 99-125 lipase. Reaction conditions: $35.4 \mathrm{mmol}$ oleic acid, $11.8 \mathrm{mmol}$ glycerol, 34.5 U lipase, $6.0 \mathrm{~mL} t$-butanol, and $6.4 \mathrm{~g} 4 \AA$ molecular sieves, $50^{\circ} \mathrm{C}, 7$ h.

reaction. In addition, in Table 2, one can view that, following purification, the products' diolein content may reach $95.1 \%$; meanwhile, the 1,3-diolein to 1,2-diolein ratio was 7.1, which was a bit less than that prior to purification (7.8). The possible reason may be that the acyl migration happened during the purification process especially in the molecular distillation which performed at a higher temperature.

When the kilogram-level experiments were conducted in a $5.0 \mathrm{~L}$ stirred tank reactor at $200 \mathrm{rpm}$ using the enlarged reaction conditions, the diolein yield and the 1,3diolein to 1,2 -diolein ratio were $70.7 \%$ and 7.5 , respectively. These slightly lower achievements may be resulted from the decreasing mass transfer efficiency between enzyme particles and substrates during a larger-scale process. Besides, based on the purification procedure, the diolein content and the 1,3 -diolein to 1,2-diolein ratio in the products could reach $94.3 \%$ and 7.2 , respectively. This undoubtedly confirmed the practicability of the enzymatic process and the efficiency of the purification strategy for the product.

\section{Conclusions}

To summarize, this research clearly showed that the $\log P$ values of the solvents displayed noticeable impact on the positional selectivity of Candida sp. 99-125 lipase in 1,3diolein synthesis by glycerol esterification of oleic acid. It is speculated that the reaction solvents with suitable polarity characteristics contributed much more significantly to Candida sp. 99-125 lipase behaviors, thus affording the promising 1,3-diolein yield. Moreover, the encouraging lipase-mediated larger-scale experiments and stability investigation suggest the possibility of using Candida sp. 99-125 lipase for the 1,3diacylglycerol industrial synthesis.

\section{Data Availability}

The data used to support the findings of this study are included within the article.

\section{Conflicts of Interest}

The authors declare that there are no conflicts of interest regarding the publication of this paper.

\section{Acknowledgments}

This work was supported by the National Natural Science Foundation of China $(21676114 ; 21706088)$, Six Talent Peaks Project of Jiangsu Province (SWYY-011), College Students Innovation and Entrepreneurship Training Projects of Jiangsu Province (SJCX17_0699), and Qing Lan Project of Jiangsu Province.

\section{References}

[1] B. L. A. Prabhavathi Devi, K. N. Gangadhar, R. B. N. Prasad, D. Sugasini, Y. P. C. Rao, and B. R. Lokesh, "Nutritionally enriched 1,3-diacylglycerol-rich oil: Low calorie fat with hypolipidemic effects in rats," Food Chemistry, vol. 248, pp. 210-216, 2018.

[2] S. Saito, A. Hernandez-Ono, and H. N. Ginsberg, "Dietary 1,3diacylglycerol protects against diet-induced obesity and insulin resistance," Metabolism - Clinical and Experimental, vol. 56, no. 11, pp. 1566-1575, 2007.

[3] T. Watanabe, M. Shimizu, M. Sugiura et al., "Optimization of reaction conditions for the production of DAG using immobilized 1,3-regiospecific lipase Lipozyme RM IM," Journal of the American Oil Chemists' Society, vol. 80, no. 12, pp. 1201-1207, 2003.

[4] C. Li, F. Zhang, Z. Gao et al., "Effects of organic solvent, water activity, and salt hydrate pair on the sn-1,3 selectivity and activity of whole-cell lipase from Aspergillus niger GZUF36," Applied Microbiology and Biotechnology, vol. 102, no. 1, pp. 225$235,2018$.

[5] Y. Zhao, J. Liu, L. Deng, F. Wang, and T. Tan, "Optimization of Candida sp. 99-125 lipase catalyzed esterification for synthesis of monoglyceride and diglyceride in solvent-free system," Journal of Molecular Catalysis B: Enzymatic, vol. 72, no. 3-4, pp. 157$162,2011$.

[6] X. Meng, G. Xu, Q.-L. Zhou, J.-P. Wu, and L.-R. Yang, "Highly efficient solvent-free synthesis of 1,3-diacylglycerols by lipase 
immobilised on nano-sized magnetite particles," Food Chemistry, vol. 143, pp. 319-324, 2014.

[7] A. Kumar, K. Dhar, S. S. Kanwar, and P. K. Arora, "Lipase catalysis in organic solvents: advantages and applications," Biological Procedures Online, vol. 2016, no. 1, article no. 2, pp. 1-11, 2016.

[8] Z.-Q. Duan, X.-L. Fang, Z.-Y. Wang, Y.-H. Bi, and H. Sun, "Sustainable Process for 1,3-Diolein Synthesis Catalyzed by Immobilized Lipase from Penicillium expansum," ACS Sustainable Chemistry \& Engineering, vol. 3, no. 11, pp. 2804-2808, 2015.

[9] D. Herbst, S. Peper, and B. Niemeyer, "Enzyme catalysis in organic solvents: Influence of water content, solvent composition and temperature on Candida rugosa lipase catalyzed transesterification," Journal of Biotechnology, vol. 162, no. 4, pp. 398-403, 2012.

[10] F. L. Joubioux, N. Bridiau, Y. B. Henda, O. Achour, M. Graber, and T. Maugard, "The control of Novozym ${ }^{\circledR} 435$ chemoselectivity and specificity by the solvents in acylation reactions of amino-alcohols," Journal of Molecular Catalysis B: Enzymatic, vol. 95, pp. 99-110, 2013.

[11] Z.-Y. Wang, Y.-H. Bi, R.-L. Yang et al., “The halo-substituent effect on Pseudomonas cepacia lipase-mediated regioselective acylation of nucleosides: a comparative investigation," Journal of Biotechnology, vol. 212, pp. 153-158, 2015.

[12] Y. Kitamoto, Y. Kuruma, K. Suzuki, and T. Hattori, "Effect of solvent polarity on enantioselectivity in Candida antarctica lipase B catalyzed kinetic resolution of primary and secondary alcohols," The Journal of Organic Chemistry, vol. 80, no. 1, pp. 521-527, 2015.

[13] L. Deng, T. Tan, F. Wang, and X. Xu, "Enzymatic production of fatty acid alkyl esters with a lipase preparation from Candida sp. 99-125," European Journal of Lipid Science and Technology, vol. 105, no. 12, pp. 727-734, 2003.

[14] K. Nie, F. Xie, F. Wang, and T. Tan, "Lipase catalyzed methanolysis to produce biodiesel: Optimization of the biodiesel production," Journal of Molecular Catalysis B: Enzymatic, vol. 43, no. 1-4, pp. 142-147, 2006.

[15] W. Du, D. Liu, L. Li, and L. Dai, "Mechanism exploration during lipase-mediated methanolysis of renewable oils for biodiesel production in a tert-butanol system," Biotechnology Progress, vol. 23, no. 5, pp. 1087-1090, 2007.

[16] R. Lortie, M. Trani, and F. Ergan, "Kinetic study of the lipase-catalyzed synthesis of triolein," Biotechnology and Bioengineering, vol. 41, no. 11, pp. 1021-1026, 1993.

[17] C. Laane, S. Boeren, K. Vos, and C. Veeger, "Rules for optimization of biocatalysis in organic solvents," Biotechnology and Bioengineering, vol. 30, no. 1, pp. 81-87, 1987.

[18] Z.-Q. Duan, W. Du, and D.-H. Liu, "The pronounced effect of water activity on the positional selectivity of Novozym 435 during 1,3-diolein synthesis by esterification," Catalysis Communications, vol. 11, no. 5, pp. 356-358, 2010.

[19] A. Küchler, M. Yoshimoto, S. Luginbühl, F. Mavelli, and P. Walde, "Enzymatic reactions in confined environments," Nature Nanotechnology, vol. 11, no. 5, pp. 409-420, 2016.

[20] A. M. Klibanov, "Improving enzymes by using them in organic solvents," Nature, vol. 409, no. 6817, pp. 241-246, 2001.

[21] A. Salihu and M. Z. Alam, "Solvent tolerant lipases: A review," Process Biochemistry, vol. 50, no. 1, pp. 86-96, 2015.

[22] G. L. Hasenhuettl and R. W. Hartel, Food Emulsifiers and Their Applications, Springer, New York, NY, USA, 2nd edition, 2008.
[23] B. Pareyt, S. M. Finnie, J. A. Putseys, and J. A. Delcour, "Lipids in bread making: Sources, interactions, and impact on bread quality," Journal of Cereal Science, vol. 54, no. 3, pp. 266-279, 2011. 


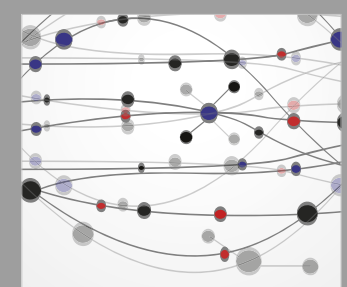

The Scientific World Journal
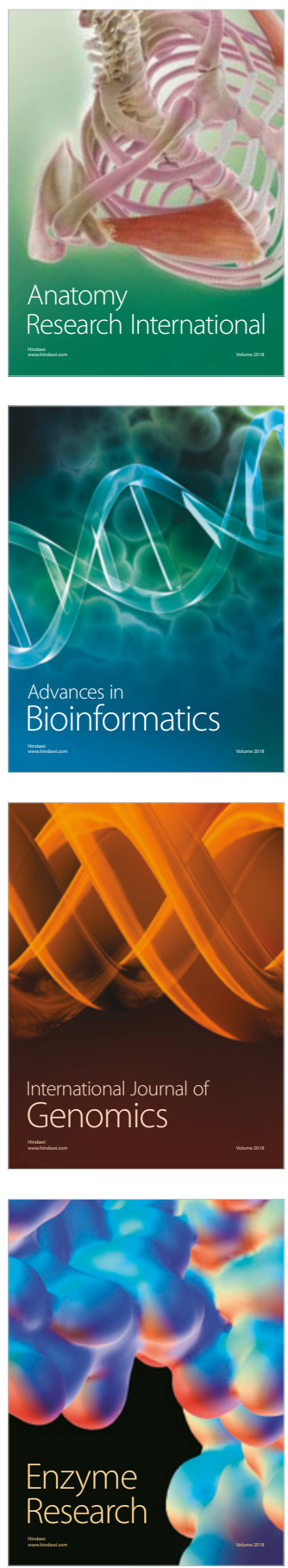
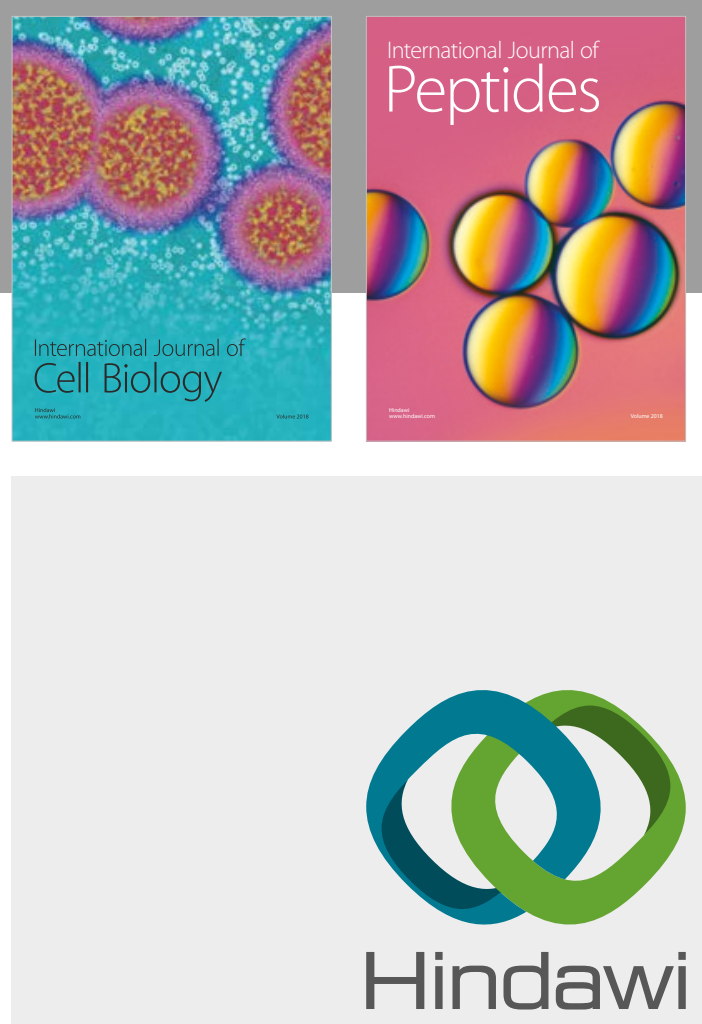

Submit your manuscripts at

www.hindawi.com
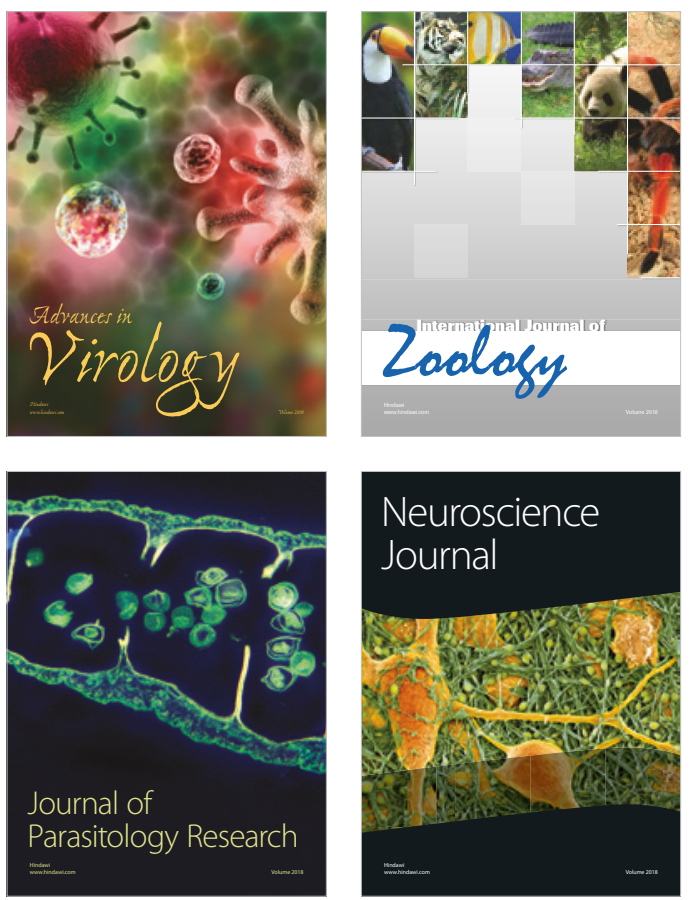
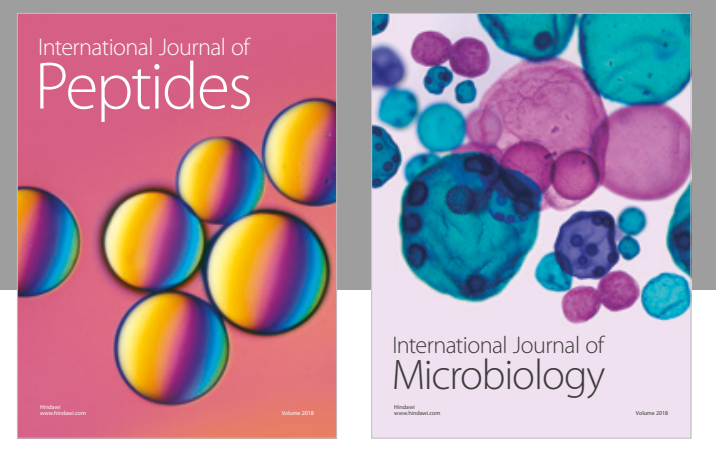

nternational Journal of Microbiology
Journal of
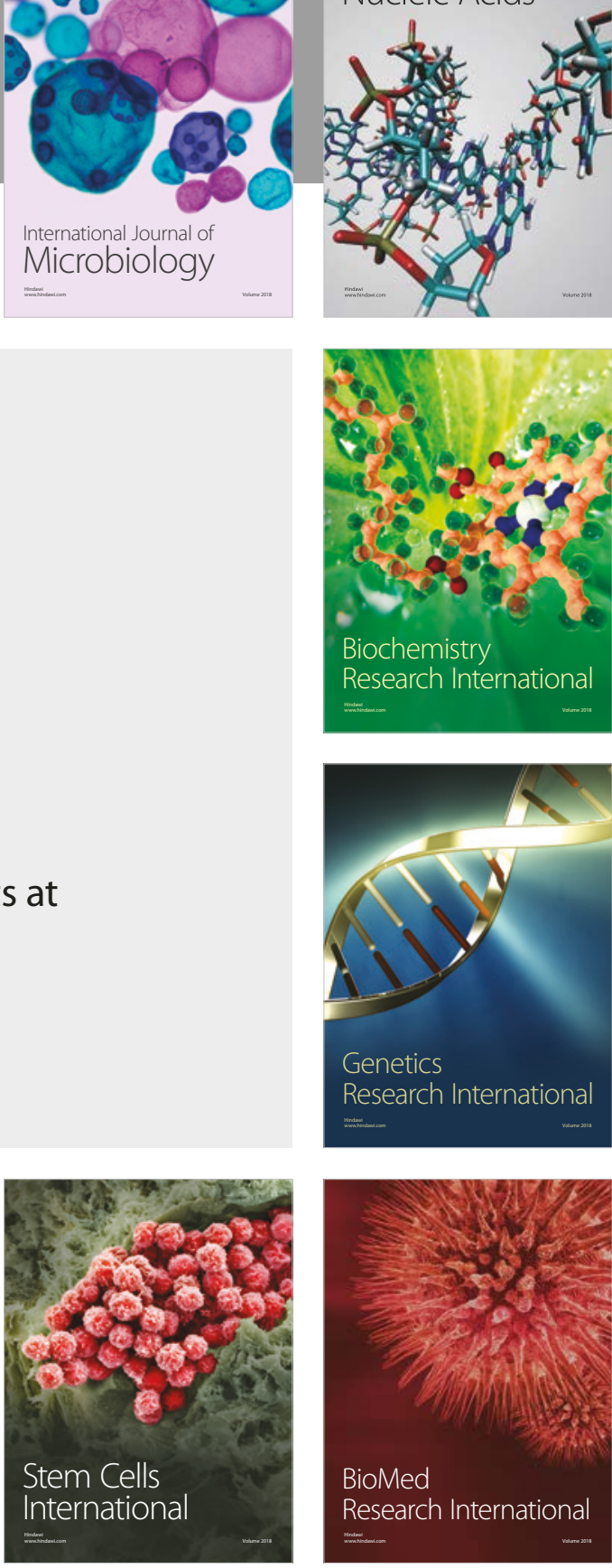
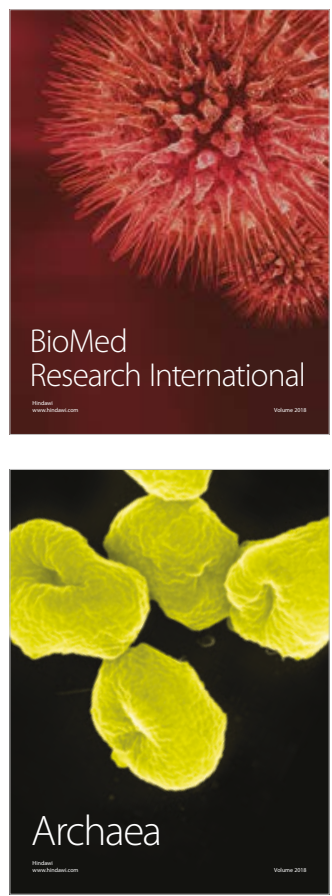